\title{
TEM with in situ Ion Irradiation of Nuclear Materials under In-Service Conditions
}

\author{
R.W. Harrison, H. Amari, G. Greaves, S.E. Donnelly and J.A Hinks
}

University of Huddersfield, Queensgate, Huddersfield, HD1 3DH, United Kingdom

Nuclear materials are subjected to extreme conditions including elevated temperatures, large numbers of atomic displacements and the introduction of gas atoms. The exact conditions faced by a material in a nuclear reactor will depend on the type of reactor, the operating conditions, elemental composition and location within the core. Atomic displacements can be measured in Displacements Per Atom (DPA) where at 1 DPA each atom has, on average, been displaced from a lattice site once. Atomic displacements are caused by the energetic products of induced nuclear reactions and of spontaneous events such as $(n, \alpha)$ or $(\mathrm{n}, \mathrm{p})$ decay. Such transmutation reactions can also introduce light-gas atoms of $\mathrm{He}$ and $\mathrm{H}$ of which $\mathrm{He}$ poses the substantially-greater problem [1]. Generally, He is insoluble in structural reactor materials, diffuses rapidly and accumulates in regions of low electron-density such as grain boundaries and vacancies [2]. The combination of temperature, atomic displacements and He accumulation leads to a complex evolution of the microstructure which can have important implications for the performance of nuclear reactor components over their operational lifetime.

Ion irradiation can be used to induce atomic displacements and introduce gas atoms such as He. This offers several advantages over neutron irradiation including the avoidance of radioactive hazards and the ability to access end-of-life DPA and He concentrations in less than a day [3]. Furthermore, such experiments can be performed in situ with other techniques such as Transmission Electron Microscopy (TEM) to directly observe the microstructure during irradiation to help understand its evolution and to elucidate the fundamental mechanisms at work [3]. Typically, the electron-transparent region of a TEM sample is less than $100 \mathrm{~nm}$ thick. An incident He ion can cause atomic displacements and if it is of sufficient energy then there is a chance that it will exit the sample causing damage without being implanted. At higher energies, the probability that it will not stop increases and thus by careful selection of ion energy the ratio of He implantation to atomic displacements (i.e. He/DPA ratio) can be tailored.

Figure 1a shows the He/DPA-ratio curves for $50 \mathrm{~nm}$ of $\mathrm{W}$ as a function of He ion energy. Shown separately for clarity, Figure $1 \mathrm{~b}$ illustrates the considerably-different results for $\mathrm{Fe} 8 \mathrm{Cr}$ and $\mathrm{SiC}$ relative to $\mathrm{W}$ (note y-axis scale compared to Figure 1a). (Calculations performed using the Stoller method [4] with SRIM-2013 for an incident angle $30^{\circ}$ off normal (see below) using displacement energies, $E_{\mathrm{d}}$, of 90 , 40, 40, 15 and $28 \mathrm{eV}$ for W [5], Fe [5], Cr [5], Si and C, respectively.) For example in magnetic-confinement fusion reactors, He/DPA ratios on the order of $10 \mathrm{appm} / \mathrm{DPA}$ are expected for alloys [6] but this rises to around 150 appm/DPA for SiC-based materials [7]. Alloys containing nickel (e.g. austenitic steels) may typically experience 100 appm/DPA [8] in a thermal-neutron spectrum but only 0.1 appm/DPA [6] when exposed to fast neutrons. Thus, although the ratio of He/DPA can vary by around three orders of magnitude, it is possible to match such conditions in TEM samples using He ion energies in the range of 40-100 keV. Performing irradiations with in situ TEM gives access to dose levels from virgin to end-oflife and the use of traditional heating holders allows access to all relevant regimes from room temperature to $1300^{\circ} \mathrm{C}$ (or higher with holders utilising MicroElectroMechanical Systems (MEMS)). Therefore it is possible to tailor experiments to explore a three-dimensional experimental-parameter space in which the three axes are temperature, He/DPA ratio and fluence (which can be equated to DPA or implanted He). To explore this parameter space, W samples prepared by electrochemical-jet polishing were irradiated 
with $60 \mathrm{keV} \mathrm{He}$ ions $(\mathrm{He} / \mathrm{DPA}=2000 \mathrm{appm} / \mathrm{DPA})$ incident at $30^{\circ}$ from the surface normal at a flux of $6.8 \times 10^{13}$ ions. $\mathrm{cm}^{-2} \cdot \mathrm{s}^{-1}$ in the Microscope and Ion Accelerator for Materials Investigations (MIAMI-1) facility (described in detail elsewhere [9]) at temperatures of 500, 750 and $1000^{\circ} \mathrm{C}$. Figure 2 shows micrographs of three irradiations to 1.0 DPA at three different points along the temperature axis. In the irradiation performed at $500^{\circ} \mathrm{C}$, the micostructure is dominated by black-spot defect clusters but at $750^{\circ} \mathrm{C}$ $\left(\approx 0.3 T_{\mathrm{m}}\right)$ resolvable bubbles are formed. At $1000{ }^{\circ} \mathrm{C}$, the bubbles exhibit a larger mean-size and lower areal-density. By filling three-dimensional matrices with such results obtained under consistent conditions for different materials, it will be possible to identify trends and predict behaviours of nuclear materials under consideration or already in-service and to guide the development of new materials.

\section{References}

[1] M.R. Gilbert, S.L. Dudarev, S. Zheng, L.W. Packer, J.-C. Sublet, Nucl. Fusion 52 (2012) p083019

[2] H. Trinkaus, B. Singh, J. Nucl. Mater. 323 (2003) p229

[3] J.A. Hinks, J. Mater. Res. 30 (2015) p1214

[4] R.E. Stoller et al., NIMB 310 (2013) p75

[5] ASTM E521-96(2009)e2

[6] L. Mansur etal., J. Nucl. Mater. 329-333 (2004) p166

[7] M.E. Sawan, Y. Katoh, L.L. Snead, J. Nucl. Mater. 442 (2013) S370

[8] E. Lee, J. Hunn, T. Byun, L. Mansur, J. Nucl. Mater. 280 (2000) p18

[9] J.A. Hinks, J.A. van den Berg, S.E. Donnelly, J. Vac. Sci. Technol. A 29 (2011) p021003

[10] J.F. Ziegler, M.D. Ziegler, J.P. Biersack NIMB 268 (2010) p1818

[11] Funded by the UK's EPSRC under grant EP/M011135/1

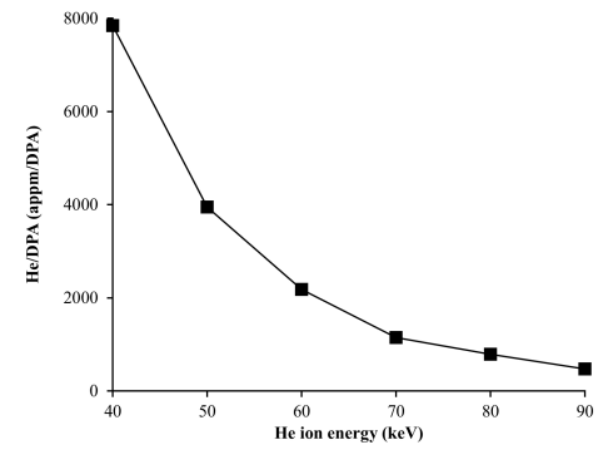

(a)

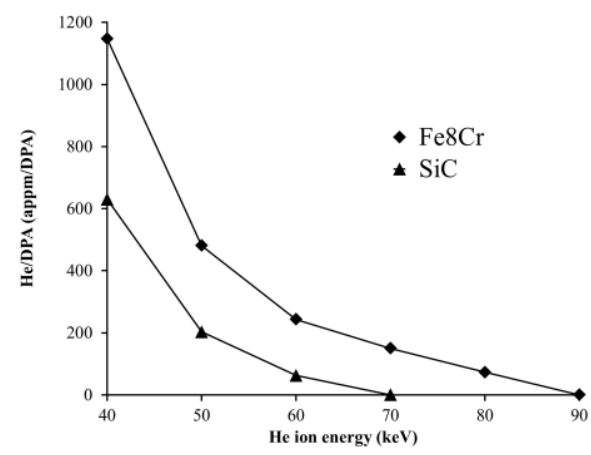

(b)

Figure 1. SRIM [10] results of He/DPA ratios versus ion energy for: (a) W; and (b) $\mathrm{Fe} 8 \mathrm{Cr}$ and $\mathrm{SiC}$.

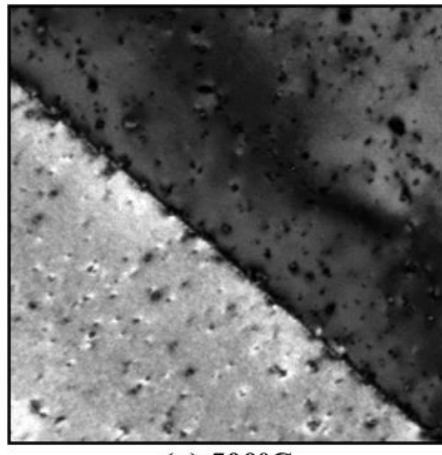

(a) $500^{\circ} \mathrm{C}$

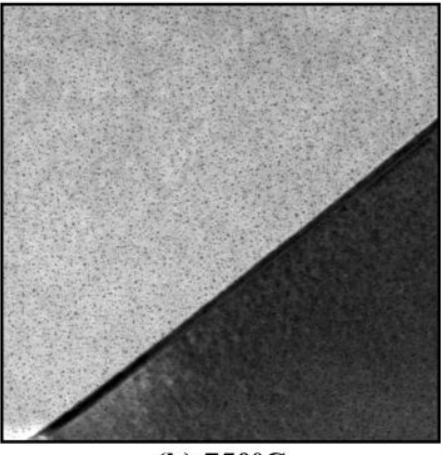

(b) $750^{\circ} \mathrm{C}$

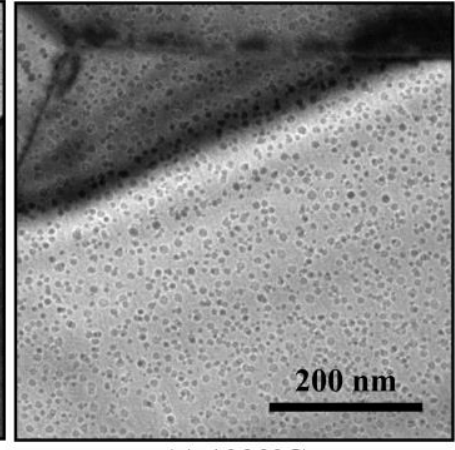

(c) $1000^{\circ} \mathrm{C}$

Figure 2. Bright-field over-focus TEM micrographs of $\mathrm{W}$ irradiated with $60 \mathrm{keV} \mathrm{He}$ ions to $1.0 \mathrm{DPA}$. 